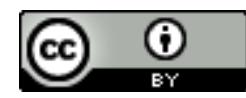

Esta obra está sob o direito de Licença Creative Commons Atribuição 4.0 Internacional.

\title{
PANTANAL NORDESTINO PACATUBENSE: CONHECER, VALORIZAR E PRESERVAR, UMA DIMENSÃO GEOGRÁFICA SOCIOAMBIENTAL.
}

\section{Cassiane Alves Santos Bispo ${ }^{1}$}

Betijane Soares de Barros ${ }^{2}$

\section{RESUMO}

Sabendo da necessidade da preservação ambiental para a manutenção da vida em nosso planeta este artigo tem como objetivo ressaltar a importância do Pantanal Nordestino, o mesmo está situado no município de Pacatuba/SE, como também enfatizar as práticas de conhecimento, pertencimento, preservação, e valorização deste bioma. A vista disso o trabalho aqui exposto está fundamentado na abordagem empírica analítica, além disto, foram realizadas pesquisas bibliográficas em sites acadêmicos como também foram feitas pesquisas de campo, pois, a pesquisa se faz indispensável na construção de trabalhos científicos já que pesquisar é executar uma investigação minuciosa com intuito de obter novos conhecimentos para assim desenvolver um trabalho relevante como também esclarecer o que antes estava obscuro podendo desta forma intervir de modo significativo. Contudo, fica evidente que a mudança tão desejada quanto à preservação ambiental do Pantanal Pacatubense se faz com o envolvimento de toda comunidade como também daqueles que visitam ou desejam visitar esse bioma visto que esse ambiente é de fundamental importância para várias espécies incluindo a espécie humana. Portanto, à vista disso o conhecimento acerca do Pantanal Nordestino vem a contribuir de forma significativa fazendo com que haja o comprometimento de todos na preservação do mesmo.

Palavras - Chave: Pantanal Pacatubense. Educação Ambiental. Preservação Ambiental.

\footnotetext{
profcassiane2014@gmail.com

2 bj-sb@hotmail.com
} 


\section{INTRODUÇÃOO}

Este artigo tem como premissa enfatizar o ambiente intitulado Pantanal Nordestino o qual encontrasse no Município de Pacatuba/SE destacando sua importância para o meio ambiente por abrigar uma grande diversidade de animais e plantas sendo considerado berçário natural para várias espécies como também por contribuir, por ser meio de sobrevivência das comunidades as quais encontrassem ao seu redor e por ser atração turística (Correia, 2016).

A vista disto, destacamos a importância de se conhecer para preservar. O Pantanal de Pacatuba/SE está localizado entre a foz do rio São Francisco e a Reserva de Santa Isabel, banhado pelas águas do rio Poxim, um afluente do Velho Chico (Rio São Francisco). Sendo composto por um total de $50 \mathrm{~km}^{2}$, destes $40 \mathrm{~km}^{2}$ partindo do povoado Areia Branca até o Mirante do Robalo onde o município de Pacatuba faz fronteira com Pirambú e $10 \mathrm{~km}^{2}$ partindo do povoado Areia Branca até o Morro do Urubu Povoado Betume onde ocorre o limite territorial com o município de Neópolis. Esse percurso reúne pântanos, manguezais, dunas, mar e Mata Atlântica formando um cenário harmonioso de fauna e flora (Ross, 2006).
O "Pantanal Nordestino" teve suas belezas expostas no programa Globo Rurais com a reportagem intitulada: "Belezas do Pantanal de Pacatuba/SE incluem 46 lagoas de água doce" da rede globo de televisão e exposto no site G1 da mesma emissora no dia 13/12/2015 às 09h15. Além disto, diversos sites de viagens destacam as belezas e peculiaridades desse ambiente. Entretanto, mesmo com a visita de pessoas das mais diversas localidades, muitos munícipes desconhecem a existência desse bioma, alguns já ouviram algo sobre, porém não compreendem realmente do que se trata e qual a importância (Correia, 2016).

Nesse sentido, tivemos como unidade de análise as comunidades as quais estão situadas no Pantanal Pacatubense já que esse ambiente requer um olhar diferenciado e compreensivo com sua especificidade sendo o mesmo único no nordeste brasileiro e por receber visitações que podem modifica-lo se não tiver as devidas orientações e precauções (Ross, 2006).

Portanto, fica evidente a necessidade de práticas de preservação com foco na diversidade local tendo como suporte teórico os estudos da dinâmica ambiental. A vista disto é de fundamental importância que se tenha inserido no currículo escolar do 
município de Pacatuba/SE o estudo do Pantanal já que em sua grande maioria os estudantes não conhecem esse ambiente e sua importância (Correia, 2016).

\section{METODOLOGIA}

A análise do bioma Pantanal de Pacatubense demandou procedimentos metodológicos que permitiu o desvelamento das suas particularidades. A vista disso a pesquisa foi fundada na abordagem empírico analítica. De acordo com Sposito (2004), essa abordagem está sistematizada a uma: articulação lógica, utilização de técnicas de coletas, técnicas descritivas, obtenção de dados secundários ou por questionários e entrevistas, nível teórico além da fundamentação teórica na forma de revisão bibliográfica e especificação das variáveis manipuladas nas situações experimentais.

Lakatos e Marconi (2010) situam que o método é o conjunto de diretrizes sistemáticas e racionais que, com mais segurança e economia, permite $\mathrm{o}$ pesquisador alcançar o objetivo proposto da sua pesquisa, logo traçando $o$ caminho a ser seguido, detecta os erros e auxilia as decisões do cientista.

O trabalho propos uma literatura dentro do marco teórico-metodológico das seguintes categorias: Interações socioambientais: CORREIA, Aracy
Losano Fontes. Os impactos socioculturais e socioambientais do turismo no ambiente costeiro: ALEXANDRE, L. M. M; MACEDO, H. S; ARAÚJO, Hélio Mário de.; Desafios na gestão ambiental: SILVA, M. S. F.; ANUNCIACAO, V. S.; ARAÚJO, Hélio Mário de. Desenvolvimento e natureza: estudos para uma sociedade sustentável. CAVALCANTI, Clóvis; A natureza do espaço: SANTOS, Milton.

Após o primeiro momento de investigação teórica foi possível aprofundar a articulação entre teoria/empiria tendo como o último procedimento a realização de trabalho de campo nas camunidades aonde o pantanal se encontra no município de Pacatuba/SE sendo que nesse momento foram focadas questões referentes ao conhecimento, preservação, recursos naturais, valorização e subsistencia.

\section{PANTANAL PACATUBENSE: CONHECER, VALORIZAR E PRESERVAR.}

O debate acerca da preservação ambiental e uso sustentável dos recursos naturais encontrasse em evidencia devido a sua necessidade para que aconteça a continuidade da vida em nosso planeta. Sendo assim, a justificativa em investigar a preservação e a diversidades da fauna e da flora 
existentes no Pantanal de Pacatuba/SE surge por perceber o pouco conhecimento local sobre esse ambiente, sua importância e o aumento do fluxo turístico.

Correia (2016, p. 91) destaca:

Em Pacatuba, a planície fluviolagunar tornou-se alvo de grande interesse para o turismo, sendo conhecida como Pantanal de Pacatuba ou Pantanal do Nordeste. Constitui-se num ambiente de $40 \mathrm{~km}$ de área ocupando os municípios de Pacatuba e Ilha das Flores, dotado de recursos hídricos e pesqueiros importantes, da fauna composta por inúmeras espécies de aves e animais silvestres como o jacaré-de-papoamarelo, lontras, capivaras e macaco-prego.

\section{Desta forma destacamos a} importância de um olhar investigativo para esse ambiente com suas contribuições para um debate profundo com os resultados dessas investigações, bem como de proporcionar a amplitude e sensibilidade em compreender as práticas de vivencias e suas dinâmicas nesse bioma muito rico em biodiversidade.

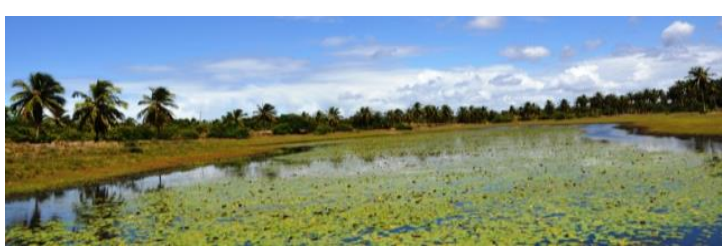

Fonte: http://www.klimanaturali.org/2014/10/

pantanal-de-pacatuba-o-pantanal.html

\section{Diante disto destacamos a} necessidade de práticas socioambientais relevantes que deve estar presente no contexto das comunidades inseridas nesse ambiente enfatizando um trabalho de conscientização através da educação ambiental começando pelas escolas e estendendo-se por toda comunidade através de palestras, apresentações de dados, rodas de conversas e debates dirigidos a fim de que haja a compreensão de que o modo que os recursos naturais oferecidos por esse bioma são utilizados pode vim a contribuir para que aconteçam grandes danos podendo chegar até à extinção de espécies animais e vegetais nativos.

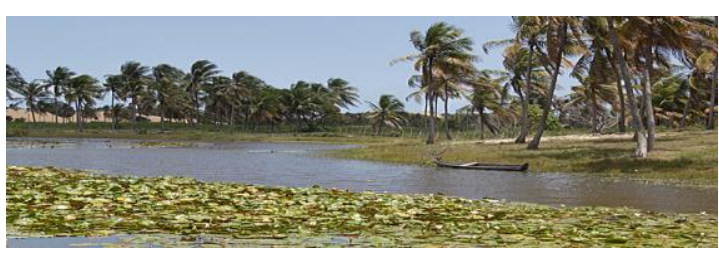

Fonte: https://www.viajenaviagem.com/2010/09/

pacatuba-o-pantanal-sergipano/

Contudo, além disto, é preciso compreender que a inserção do turismo de forma desordenada acarreta em impactos muitas vezes irreversíveis, sendo assim enfatizamos a importância do reconhecimento que são necessários cuidados específicos para que o respeito à natureza seja algo concreto, desta forma as visitas devem ser acompanhadas e orientadas por guias credenciados.

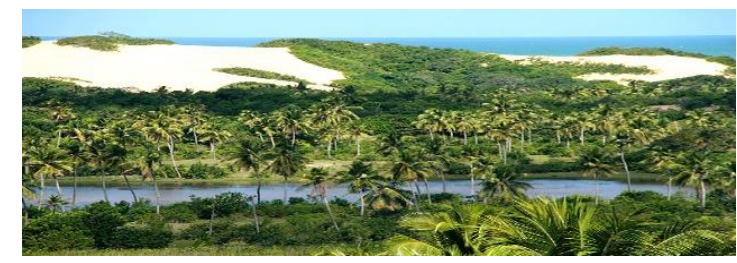

Fonte: https://www.sergipeturismo.com/pantanal-depacatuba/ 
A vista disto é preciso abordar o tema Pantanal Nordestino em todos os níveis de ensino já que a educação ambiental é algo indispensável e de suma importância para a manutenção da vida de todas as espécies, sendo assim, é um conteúdo que pode ser trabalhado de forma interdisciplinar sendo abordado por diversas áreas, porem destacamos aqui a Geografia com enfoque na dinâmica ambiental, que, segundo Mendonça, (2002, p. 140):

O objetivo do estudo da geografia socioambiental, construto contemporâneo da interação entre natureza e sociedade, não pode ser concebido como derivado de uma realidade onde seus dois componentes sejam enfocados de maneira estanque e independente, pois é a relação dialética entre eles que dá sustentação ao objeto.

Neste sentido, de acordo com o autor a interação entre a natureza e a sociedade é algo indissociável já que tem ocorrido muita interferência humana em ambientes antes intocados e isso tem acarretado desequilíbrio na diversidade e consequentemente desastres ambientais.

Para Correia, (2016, p.1):

As interações humanas com a natureza desenvolvem-se, essencialmente, pelas formas e condições de ocupação do território, da apropriação dos recursos naturais e da organização social adotada para o atendimento das necessidades expressas pelo padrão de consumo de cada sociedade.

A vista disto, destacamos a importância de reconhecer que as sociedades vêm ao logo de tempo realizando grandes intervenções sem pensar nas consequências que as mesmas venham acarretar para o meio ambiente e com isso para toda forma de vida existente.

Como afirma Ross (2006, p. 50).

A fragilidade dos ambientes naturais diante das intervenções humanas é maior ou menor em função de suas características genéticas. Em princípio, salvo algumas regiões do planeta, os ambientes naturais mostravam-se em estado de equilíbrio dinâmico até o momento em que as sociedades humanas passaram a intervir, cada vez mais intensamente, na exploração dos recursos naturais para gerar riquezas, conforto, prazer e lazer.

Sendo assim, destacamos a necessidade de se conhecer para preservar e valorizar o Pantanal de Pacatuba/SE, entretanto consideramos a importância desse conhecimento e valorização partir do local para o global já que os munícipes convivem com esse bioma sem saber qual a sua verdadeira relevância. Contudo na Constituição Federal de 1988 em seu artigo 225 destaca,

Todos têm direito ao meio ambiente ecologicamente equilibrado, bem de uso comum do povo e essencial à sadia qualidade de vida, impondo-se ao Poder Público e à coletividade o dever de defendê-lo e preservá-lo para as presentes e futuras gerações. (BRASIL, 1988).

A vista disto, compreendemos o uso adequado dos recursos naturais como algo extremamente relevante já 
que sem sendo enfatizado há bastante tempo não somente em debates como também em documentos oficias como é o caso da constituição federal de 1988, visto que é impossível se ter um meio ambiente ecologicamente equilibrado sem utilização de uma educação voltada para esse fim.

Para Santos, M. (2004, p.233):

A história das chamadas relações entre sociedade e natureza é, em todos os lugares habitados, a da substituição de um meio natural, dado a uma determinada sociedade, por um meio cada vez mais artificializado, isto é, sucessivamente instrumentalizado por essa mesma sociedade.

Sendo assim, vale destacar que a educação ambiental vem sendo muito significativa por causa da conexão não equilibrada entre o ser humano e a natureza. "Estudos têm mostrado que ações educativas relacionadas ao ambiente natural apresentam ganhos cognitivos, mudança de valores e auxiliam na construção da consciência social e individual" (FONSECA, 2007, p.67 apud PÁDUA, TABANEZ, 1997; TILBERY, 1999; BECKER, ELLIOT, 2000; NKOSKI, 2002).

Contudo para Correia, (2016, p.104):

As relações sociedade-natureza, objeto da Geografia, desempenham papel importante para a produção do conhecimento humano bem como para a apreensão da totalidade, que se constitui um elemento fundamental para a análise da realidade.
Entretanto, é preciso utilizar diferentes fontes de informações permitindo uma série de ações com intuito de que haja engajamento da comunidade em preservar e valorizar o Pantanal de Pacatuba/SE vivenciando a sustentabilidade empregando a educação como o dispositivo certificador.

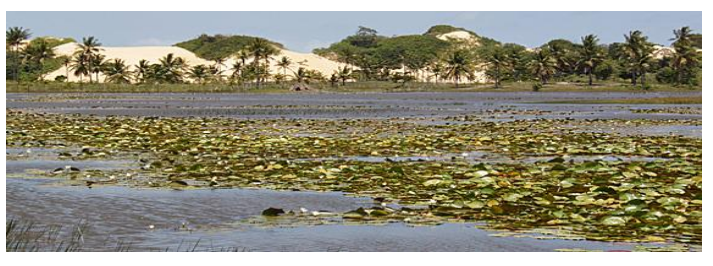

Fonte: https://www.viajenaviagem.com/2010/09

/pacatuba-o-pantanal-sergipano/comment-page-1/

Contudo destacamos a importância deste bioma para as artesãs que moram nas comunidades inseridas entorno do mesmo, pois fazem seus trabalhos a partir da fibra da Taboa ou Pau-de-Lagoa (Typha Domingensis) planta nativa que se encontra nas lagoas e lagos do Pantanal Pacatubense.

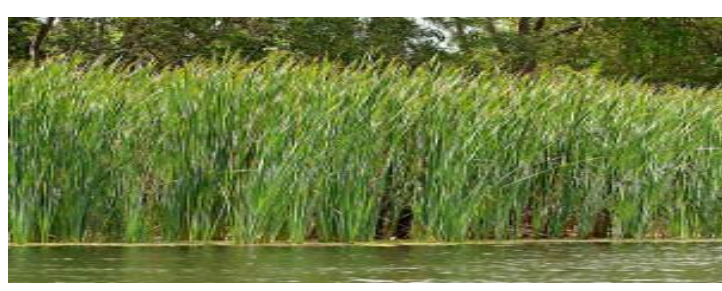

Fonte: https://www.fazfacil.com.br/jardim/taboatypha-domingensis/

Para conseguir a matéria prima para confecção de peças como: bolsas de vários tipos e tamanhos, chapéus, carteiras, porta-moeda, porta lápis, 
tapetes, sandálias, chaveiros, vasos para flores, bijuterias, entre outras, é preciso fazer a retirada da planta sendo um processo o tanto quanto perigoso o qual as artesãs realizam para que seus artesanatos venham a serem concretizados já que esse material se encontra num habitat natural de cobras, jacarés e outros animais, sem falar no perigo de afogamento e contaminação nas águas das lagoas e lagos.

Portanto o Pantanal Nordestino além de ser berçário para diversas espécies para é de suma importância para subsistência das comunidades, pois além da taboa utilizada em peças artesanais oferece peixes e outros animais que são utilizados na alimentação.

\section{CONCLUSÃO}

Diante das pesquisas feitas para a realização deste trabalho podemos afirmar a importância do bioma Pantanal Nordestino ou Pantanal Pacatubense para a conservação de diversas espécies da fauna e da flora nativa como também da sobrevivência das comunidades que se encontram inseridas nesse ambiente.

Desta forma é preciso reconhecer que a educação ambiental é o meio eficaz para garantir o envolvimento dos munícipes nesse ato de respeito e valorização. Contudo destacamos a escola como o espaço adequado para que esse tema seja enfatizado e assim aconteça a disseminação já que nossas crianças e jovens precisam tornassem adultos respeitosos com relação ao meio ambiente destacando aqui o Pantanal Pacatubense e todas as espécies ali existentes sem distinção sendo essas pertencentes à fauna ou a flora.

Toda via mesmo no município de Pacatuba/SE há quem desconheça esse ambiente enfatizando assim ainda mais a necessidade de serem realizadas palestras e demais eventos envolvendo toda sociedade afim de que esse importante berçário para diversas espécies seja conhecido, preservado e valorizado.

Portanto reafirmamos a importância de se conhecer para preservar e valorizar esse bioma único e de valor inestimável para os munícipes de Pacatuba/SE como também para toda a humanidade por se tratar de um ambiente rico em diversidade.

\section{REFERENCIAS}

ALEXANDRE, L. M. M.; MACEDO, H. S.; ARAÚJO, Hélio Mário de. Os impactos socioculturais e socioambientais do turismo no ambiente costeiro: um olhar para o Litoral Sul Sergipano. CONFINS (PARIS), v. 41, p. 1-20, 2019.

BRASIL. Constituição da República Federativa do Brasil de 1988. Brasília, DF, 5 out. 1988. Disponível em: http://www.planalto.gov.br/ccivil_03/consti 
tuicao/ConstituicaoCompilado.htm. Acesso em: 23 set. 2020.

BRASIL. Lei $\mathrm{n}^{\circ}$ 9795, de 27 de abril de 1999. Política Nacional de Educação

Ambiental. Disponível em: http://www.planalto.gov.br/ccivil_03/leis/19 795.htm Acesso em: 23 set. 2020.

\section{CAPRA, F. Alfabetização Ecológica: O} desafio para a educação do século 21. In: TRIGUEIRO, A. et al. Meio ambiente no século 21: 21 especialistas falam da questão ambiental nas suas áreas de conhecimento. 5. ed. Campinas: Armazém do Ipê (autores Associados), 2008. Cap. 1.p. 19-33.

CAVALCANTI, Clóvis (Org). Desenvolvimento e natureza: estudos para uma sociedade sustentável. São Paulo: Cortez, 1995.

CORREIA, Aracy Losano Fontes. Interações socioambientais da planície costeira associadas à foz do Rio São Francisco-Município de Pacatuba-SE. Tese de doutorado em Geografia. São Cristóvão: 2016. Universidade Federal de Sergipe: UFS.

FONSECA, M.J.C.F. A biodiversidade e o desenvolvimento sustentável nas escolas do ensino médio de Belém (PA), Brasil. Educ. Pesqui., [s.1.], v. 33, n. 1, p.63-79, abr. 2007. FapUNIFESP (SciELO). DOI: 10.1590/s1517-97022007000100005.

Disponível em: http://www.scielo.br/scielo.php?script=sci_ arttext\&pid=S1517$97022007000100005 \& \operatorname{lng}=$ pt\&nrm=iso\&tl ng=pt. Acesso em: 20 Set 2020.

LAKATOS, E. M; MARCONI, M, A. Fundamentos de metodologia cientifica. $7^{\mathrm{a}}$ ed-São Paulo. Atlas, 2010.

MENDONÇA, F. Geografia socioambiental. In: Francisco Mendonça e Salete Kozel (orgs). Elementos de epistemologia da geografia contemporânea. Curitiba: Ed. da UFPR, 2002.

RAFFESTIN, C. Por uma geografia do poder. Tradução de Maria Cecília França. São Paulo: Ática, 1993.

ROSS. J. L. S. Ecogeografia do Brasil: subsídios para o planejamento ambiental. São Paulo: Oficina de Textos, 2006.

SANTOS, M. A natureza do espaço: técnica e tempo, razão e emoção. 4. ed. São Paulo, EDUSP, 2004.

SILVA, M. S. F.; ANUNCIACAO, V. S.; ARAÚJO, Hélio Mário de. Desafios na gestão ambiental participativa em unidades de conservação, Brasil. geografar Revista Eletrônica do Programa de Pós-Graduação em Geografia da UFPR, v. 15, p. 195-219, 2020.

SOUZA, E.A. PEDON, N.R. Território e identidade. Revista Eletrônica da Associação dos geógrafos brasileiros. Seção Três Lagoas/MS, 2007.

SPOSITO, E. S. Geografia e filosofia: Contribuições para o ensino do pensamento geográfico. São Paulo. Ed UNESP, 2004. 